\title{
Sickle Cell Disease Complicated by Iron Overload: An Under-Recognized Risk Factor for Vibrio vulnificus Infection
}

\author{
Firas El Chaer Noa G. Holtzman Maria R. Baer Ann B. Zimrin Jennie Y. Law \\ University of Maryland Greenebaum Comprehensive Cancer Center, University of Maryland School of Medicine, \\ Baltimore, MD, USA; Department of Medicine, University of Maryland School of Medicine, Baltimore, MD, USA
}

Patients with sickle cell disease (SCD) often receive unnecessary red blood cell (RBC) transfusions leading to complications which include alloimmunization, hyperhemolysis, and iron overload [1-3]. An under-recognized risk of iatrogenic iron overload in patients with SCD is an increased susceptibility to infections with siderophilic, or "iron-loving," bacteria. Here we present a patient with SCD who developed septicemia with Vibrio vulnificus, a previously unreported complication in patients with SCD and acquired iron overload from repeated RBC transfusions.

A 28-year-old African American man with SCD (HbSS), complicated by recurrent vaso-occlusive pain crises as well as hepatic dysfunction and cirrhosis secondary to iron overload, presented to our medical center with acute onset of high-grade fever and worsening abdominal pain. The patient was intermittently compliant with hydroxyurea therapy and had required both simple and exchange RBC transfusion to manage his SCD. He had biopsy-proven hepatic dysfunction and cardiomyopathy due to iron overload. He initially established care at our institution for evaluation of liver transplant. He was receiving dual iron chelation therapy with oral deferiprone and continuous infusion deferoxamine to improve pretransplant organ function. On presentation, the physical examination was remarkable for tachycardia and scleral icterus. His hemo- globin was $3.8 \mathrm{~g} / \mathrm{dL}$ (baseline $7.0 \mathrm{~g} / \mathrm{dL}$, normal range 12.6-17.4), white blood cell count was $25 \times 10^{9} / \mathrm{L}$ (normal range $4.5-11$ ), and lactic acid was $8.8 \mathrm{mmol} / \mathrm{L}$ (normal range $0.5-1.6)$. He was started on broad-spectrum antibiotics, but rapidly developed respiratory failure and septic shock. Blood cultures grew $V$. vulnificus. Upon further questioning, the patient's family reported that he had prepared and eaten crabs a few days prior to the onset of symptoms. His hospital course was complicated by multiorgan dysfunction and death.

In the USA, infection with $V$. vulnificus is the leading cause of shellfish-associated death [4]. V. vulnificus is a Gram-negative bacterium primarily associated with wound infections and characterized by rapidly progressive hemorrhagic bullae and septicemia with mortality rates as high as $80 \%$ [5]. The bacterium is particularly virulent in patients with liver disease, iron storage disorders, human immunodeficiency virus, cancer, diabetes, and thalassemia [6, 7]. Liver disease is a risk factor due to both decreased glutathione and cytokine production, resulting in poor bloodstream clearance of the bacterium [8]. In iron-rich conditions, $V$. vulnificus grows exponentially, particularly when transferrin exceeds $70 \%$ [9]. V. vulnificus can be inhibited by deferiprone or deferasirox; however, it is stimulated by deferoxamine through the outer membrane DesA receptor [10-12].
In patients with SCD complicated by iron overload, infection with $V$. vulnificus should be suspected if patients present with sepsis, diarrhea, or wound infections following seafood consumption, particularly during warmer seasons. It is imperative to warn patients with SCD regarding the risks of handling and ingesting raw or undercooked shellfish. Providers must be cognizant that iron chelators can potentiate the virulence of $V$. vulnificus infection. Hematologists caring for patients with SCD complicated by iron overload should include $V$. vulnificus infection in their differential diagnosis when evaluating patients presenting with septicemia following recent seafood consumption.

\section{Disclosure Statement}

The authors declare no competing financial interests.

\section{Author Contributions}

All authors cared for the patient; F.E.C and J.Y.L developed the first draft of the manuscript; N.G.H., M.R.B., and A.B.Z. helped edit the manuscript. All authors provided critical revisions, gave final approval, and agreed to be accountable for the work.

\section{KARGER}

(C) 2018 S. Karger AG, Basel
Jennie Y. Law, MD

University of Maryland School of Medicine

Marlene and Stewart Greenebaum Comprehensive Cancer Center

22 South Greene Street, Room S9D15C, Baltimore, MD 21201 (USA)

www.karger.com/aha 


\section{References}

1 Narbey D, Habibi A, Chadebech P, Mekontso-Dessap A, Khellaf M, Lelievre JD, et al: Incidence and predictive score for delayed hemolytic transfusion reaction in adult patients with sickle cell disease. Am J Hematol 2017; 92:1340-1348.

-2 Vichinsky EP, Earles A, Johnson RA, Hoag MS, Williams A, Lubin B: Alloimmunization in sickle cell anemia and transfusion of racially unmatched blood. N Engl J Med 1990;322: 1617-1621.

$>3$ Harmatz P, Butensky E, Quirolo K, Williams R, Ferrell L, Moyer T, et al: Severity of iron overload in patients with sickle cell disease receiving chronic red blood cell transfusion therapy. Blood 2000;96:76-79.

4 Mead PS, Slutsker L, Dietz V, McCaig LF, Bresee JS, Shapiro C, et al: Food-related illness and death in the United States. Emerg Infect Dis 1999;5:607-625.
5 Dechet AM, Yu PA, Koram N, Painter J: Nonfoodborne Vibrio infections: an important cause of morbidity and mortality in the United States, 1997-2006. Clin Infect Dis 2008;46: 970-976.

6 Menon MP, Yu PA, Iwamoto M, Painter J: Pre-existing medical conditions associated with Vibrio vulnificus septicaemia. Epidemiol Infect 2014;142:878-881.

7 Centers for Disease Control and Prevention: Vibrio species causing vibriosis: people at risk. 2017. https://www.cdc.gov/vibrio/people-atrisk.html (accessed March 19, 2018).

8 Powell JL, Strauss KA, Wiley C, Zhan M, Morris JG Jr: Inflammatory cytokine response to Vibrio vulnificus elicited by peripheral blood mononuclear cells from chronic alcohol users is associated with biomarkers of cellular oxidative stress. Infect Immun 2003; 71:4212-4216.
Brennt CE, Wright AC, Dutta SK, Morris JG Jr: Growth of Vibrio vulnificus in serum from alcoholics: association with high transferrin iron saturation. J Infect Dis 1991;164:10301032.

10 Kim CM, Park YJ, Shin SH: A widespread deferoxamine-mediated iron-uptake system in Vibrio vulnificus. J Infect Dis 2007;196:15371545.

11 Kim CM, Park RY, Choi MH, Sun HY, Shin $\mathrm{SH}$ : Ferrophilic characteristics of Vibrio $\mathrm{vul}$ nificus and potential usefulness of iron chelation therapy. J Infect Dis 2007;195:90-98.

12 Neupane GP, Kim DM: Comparison of the effects of deferasirox, deferiprone, and deferoxamine on the growth and virulence of Vibrio vulnificus. Transfusion 2009;49:1762-1769. 